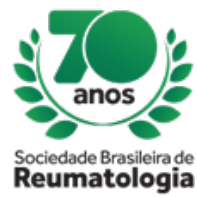

\title{
MALIGNANT SYPHILIS IN A LUPUS PATIENT USING RITUXIMAB
}

Daniel Viana da Silva e Silva (UNIFESP, São Paulo, SP, Brasil), Raquel Mitie Kanno (UNIFESP, São Paulo, SP, Brasil), Luíza Sá e Rêgo Tupinambá (UNIFESP, São Paulo, SP, Brasil), Mariana Davim Ferreira Gomes (UNIFESP, São Paulo, SP, Brasil), Igor Beltrão Duarte Fernandes (UNIFESP, São Paulo, SP, Brasil), Germana Ribeiro Araujo Carneiro Lucena (UNIFESP, São Paulo, SP, Brasil), Renan Rodrigues Neves Nascimento (UNIFESP, São Paulo, SP, Brasil), Lísel Gottfried Mallmann (UNIFESP, São Paulo, SP, Brasil), Alexandre Lima Matos (UNIFESP, São Paulo, SP, Brasil), Edgard Torres dos Reis Neto (UNIFESP, São Paulo, SP, Brasil)

\section{BACKGROUND}

Malignant syphilis is a rare and aggressive form of secondary syphilis, its commonly associated with systemic features. Its name derives from the similarity with some cutaneous neoplasms. Patients with this disease usually have immunodeficiency due to HIV. However other causes of immunosuppression, such as rituximab, can be associated.

\section{CASE REPORT}

A 28 years old female, previously diagnosed with systemic erythematosus lupus, using hydroxychloroquine and rituximab since january 2016 for hematologic activity, thrombocytopenia and muco-cutaneous bleeding, which were nonresponsive to intravenous immunoglobulin in association with $1 \mathrm{mg} / \mathrm{kg} /$ day of prednisone. In july 2018 she presented with erythematous and prickly lesions initially on both shoulders, then spreading to the whole body, associated with malaise, fatigue and arthritis on right wrist and knee. It was hypothesized it could be drug allergy, pityriasis rosea or syphilis. Serology for HIV, CMV, hepatitis, toxoplasmosis and syphilis were taken. The dermatology evaluated and a skin biopsy was done. The initial serology was negative, except for the treponemal antigen test which was positive, and the biopsy showed nonspecific interface dermatitis. Considering drug allergy the most probable cause, it was initiated $40 \mathrm{mg}$ prednisone, topic betamethasone and the rituximab dose was postponed. Methotrexate was associated due to arthritis. In september there were no significant improvement, the serology was once again done, with the same outcome. In November, she presented febrile, with purulent rhinorrhea, odynophagia, redness on the right eye, the skin lesions were maintained and new scaly and exudative lesions on both arms and legs emerged, with secondary infection signs, therefore she was sent for hospital admission. The fundoscopy showed signs of retinal vasculitis on the right eye and VDRL was positive with titer of 1:16. Lumbar puncture wasn't done, because there were lesions at the site of access. The patient received 14 days of ceftriaxone and 7 days of oxacillin, the immunosuppressants were discontinued and she evolved with clinical resolution, confirming malignant syphilis. In december, the hydroxychloroquine was returned, there was no sign of lupus activity, so she remains without rituximab.

\section{CONCLUSION}

This report describes a case of malignant syphilis with good response to antibiotic. The patient had low titer of VDRL, which isn't normally observed on literature, perhaps the excess of antibody in the serum justify the result (prozone phenomenon). This rare case remembers that syphilis should always be reminded as a differential diagnose with disease activity. 